\title{
PARADOXO E NATUREZA NO LIVRO V DA REPÚBLICA ${ }^{l}$
}

\author{
Marcelo P. Marques* \\ marquess56@yahoo.com.br
}

\begin{abstract}
RESUMO $O$ artigo analisa a primeira onda do livro $V$ da República de Platão, levando em conta a oposição entre opinião (dóxa) e ciência (epistéme), só formulada ao final da terceira onda. Sócrates problematiza a opinião corrente que aceita a diferença de natureza entre homens e mulheres para avançar a ideia de uma natureza humana comum. É essa tese paradoxal que justifica que possam ter uma mesma educação e que, assim, possam desempenhar as mesmas funções, vindo a ser guardiões e governantes da cidade.
\end{abstract}

Palavras-chave Platão, República, natureza, opinião, ciência.

ABSTRACT The paper analyses the first wave in Plato's Republic $V$, taking into account the opposition between opinion (doxa) and science (episteme), formulated at the end of the third wave. Socrates questions the current opinion which accepts the difference in nature between men and women in order to propose the idea of a common human nature. It is this paradoxical thesis that justifies the proposal that all should have the same education, thus allowing them to fulfill the same functions and, eventually, to become guardians and rulers in the city.

Keywords Plato, Republic, nature, opinion, science.

1 Uma primeira versão deste texto foi apresentada no Simpósio Phýsis - Natura, promovido pelo Grupo de Filosofia Antiga da UFMG, em Maio de 2009.

* Professor do Departamento de Filosofia da UFMG. Recebido em 04/05/2010 e aprovado em 05/06/2010.

KRITERION, Belo Horizonte, nº 122, Dez./2010, p. 429-440. 
O núcleo da argumentação do livro V da República consiste em desenvolver uma sucessão de três ondas (trikymía) ou teses que exigem uma interpretação mais detalhada por parte do leitor pela perplexidade que causam. Sócrates propõe e defende três posições frontalmente contrárias ao que é comumente aceito pela cidade, três paradoxos, na medida em que são contrárias à dóxa hegemônica: a igualdade funcional entre homens e mulheres, a comunidade de mulheres e o governo dos filósofos. Neste artigo, proponho-me ler a primeira onda (451C-457C), sobre as diferenças e semelhanças de natureza entre homens e mulheres, à luz da terceira, a que propõe o governo dos filósofos, acreditando que uma ajuda a esclarecer a outra.

\section{A terceira onda esclarece a primeira}

No final do livro V (476E-478E), para sustentar o terceiro e último paradoxo, Sócrates desenvolve a conhecida argumentação que estabelece diferentes modos de ser e de conhecer; sua estratégia argumentativa é distinguir opinião de ciência (dóxa - epistéme), postulando diferenças a partir de seus objetos. ${ }^{2}$ É essa diferenciação que sustenta a proposta segundo a qual quem deve governar a cidade são aqueles que têm uma natureza filosófica, tal como será longamente defendido no livro VI (486A-E); trata-se, portanto, de uma argumentação política, que visa, em última instância, a persuadir os leitores / auditores que quem deve assumir o poder são indivíduos que têm uma relação bem particular com o saber. O que proponho é que a análise da primeira onda prepara e já exemplifica a questão mais ampla das relações entre ser e aparecer, formulada aqui como a oposição entre opinião e ciência, uma diferenciação que é praticada amplamente por Platão na escrita dos diálogos e teorizada no final deste livro em particular.

Depois de ter delimitado (diaperanthèn) o drama dos homens, Sócrates e seus interlocutores passam ao drama das mulheres (451B). Começa então a examinar a possibilidade de as mulheres serem guardiãs; Sócrates fala segundo o que lhe parece (kat'emèn dóxa), ou segundo sua própria opinião. É assim que ele vai nos conduzir da opinião geral a algo contrário a ela, ou seja, a algum paradoxo.

Se examinaram os homens como guardiões de um rebanho, devem ser conseqüentes e atribuir às mulheres um nascimento e uma educação semelhantes. Sócrates começa pela analogia com os cães, cujas fêmeas vigiam e caçam, fazendo tudo em comum com os machos; elas não ficam dentro de 
casa, pensando que parir e criar filhotes as torna incapazes; pelo contrário, fazem tudo em comum, embora seja preciso levar em conta que são mais fracas. Não há argumentação propriamente dita, apenas a ideia de que se entre os cães é assim, deve poder ser do mesmo modo entre homens e mulheres; a conclusão permanece no plano do parecer. Parece razoável (eikòs) que, se vão recorrer às mulheres para que exerçam as mesmas funções que os homens, é preciso que lhes seja dada a mesma educação: arte, música, treinamento mili$\operatorname{tar}(451 \mathrm{C}-452 \mathrm{~A})$.

A reflexão seguinte leva em conta um certo relativismo cultural, criticando a dóxa ou o que é considerado bom e aceitável para a educação das mulheres; estas coisas pareceriam ridiculamente contrárias ao costume (parà tò éthos geloîa àn phaínoito) se praticadas deste modo (452B). Manifestamente (dêla) é risível ver as mulheres nuas nas palestras, exercitando-se junto com os homens; trata-se de uma cena não agradável à vista, mulheres e velhos nus em público. Sócrates dirá que não se devem temer as mudanças nos costumes, que o que é risível é relativo, variando com a época e a educação recebida, que os costumes podem mudar. Lembra que, não há muito tempo, aos helenos parecia feio e risível o que, agora, (parece tal) à maioria dos bárbaros (toîs éllésin edókei aiskhrà eînai kaì geloîa háper nyn toîs polloîs tôn barbáron); ou seja, que os homens sejam vistos nus (gymnoùs ándras horâsthai) e que, quando a ginástica começou a ser praticada, os homens da cidade faziam comédia de tudo isso (452C). Depois, na prática, (a)pareceu (-1hes) (epháne que desnudar-se era melhor que esconder, ou seja, a própria experiência acabou lhes fazendo ver o que hoje é considerado verdadeiro e bom.

Aquilo que (apareceu) aos olhos risível foi apagado pelo que foi indicado (revelado) nos argumentos como sendo o melhor. ${ }^{3}$

O fato de se tratar, literalmente, de uma cena que se oferece aos olhos pode nos levar ao equívoco de pensar que a dóxa esteja restrita ao plano fenomênico literal; mas não é bem assim. A avaliação estética do que se oferece à visão envolve muito mais do que as impressões sensíveis imediatas. Leio a expressão en toîs ophtalmoîs de modo amplo, ou seja, metafórico. A oposição a en toîs lógoîs pode levar a pensar que a dóxa é de natureza diferente e oposta ao lógos; mas isto não se sustenta exatamente; sabemos que, na verdade, dóxa é doxázein, um tipo de julgamento e, nesse sentido, uma modalidade do lógos, 
ou seja, um tipo de pensamento. ${ }^{4}$ Por mais que o lógos formulado por alguém com mais ou menos experiência seja mais ou menos permeável à mistura com as percepções sensíveis, por definição, o opinar ou julgar (doxázein) é uma modalidade ou variação do discurso que vai além da "seção da dóxa" (se anteciparmos a linha dividida, do final do livro VI), sendo permeável em relação ao discurso dianoético; a dóxa acontece quando se interrompe o movimento do perguntar e responder. ${ }^{5}$ Além disso, o próprio contexto mostra o quanto se trata mais de uma questão de valoração do que de mera percepção. A percepção sensível não está aquém da esfera da cultura (paideía) e não pode, no caso, ser critério de avaliação das ações humanas. ${ }^{6}$

De qualquer modo, é pelos argumentos que se mostra (enedeíxato) que nada é risível, a não ser o que é nocivo. O comentário faz referência ao fato de se tratar de um objeto da visão. Aquele indivíduo que tenta fazer rir, considerando como risível algum espetáculo outro que o que é insensato ou nocivo para os homens (452E), está pondo como objetivo de seus esforços algo diferente do que é sensato, bom ou correto; isto sim é condenável e, eventualmente, risível. O exemplo da ginástica, no caso, é, de fato, algo a ser visto, um espetáculo ao qual se pode assistir; mas, a dimensão fenomênica não a dimensão fenomênica não exclui a dimensão judicativa ou criteriológica, ou seja, de valores e costumes que devem ser questionados racionalmente, portanto, nos e através dos argumentos, reflexivamente. Por mais que eu ame espetáculos en ophthalmoîs, trata-se da indicação de algo mais amplo e complexo: o que aparece de fato, mais do que a nudez feminina é o juízo comum sobre as mulheres, suas ações e seus hábitos. A dóxa, mais que a nudez dos corpos, domina o espaço da "visibilidade" pública enquanto dimensão axiológica amplamente compartilhada.

O sentido da discussão, no fim das contas, é que o que é bom para a cidade deve ser defendido argumentativamente e mostrado como sendo de acordo com o que é bom em si, como será indicado nos livros seguintes da República.

\section{Natureza e diferença}

A questão, portanto, é

4 Apesar de, nesta passagem da República, Sócrates não enfatizar a continuidade, sabemos que, em outros diálogos, a dóxa é definida como um tipo de julgamento, ou seja, como pertencendo ao âmbito do lógos. No Sofista, a dóxa é definida explicitamente como uma modalidade do lógos - 263E3-264B4. Ver ainda Filebo 38B-E.

5 Ver também Teeteto 189C-190A; Dixsaut, 1995.

6 Ver Maclntyre, 1991. 
... saber se a natureza humana, na mulher, é capaz de associar-se ao gênero masculino em todos os trabalhos ou em nenhum, ou se ela é capaz em alguns e não em outros, e em qual dos dois deve-se situar precisamente os trabalhos da guerra? ${ }^{7}$

Sócrates empreende então a contestação da própria posição, acusando-se de contradição.

- É, pois, verdade que a mulher não difere de modo algum do homem em relação à natureza? - Como poderia ela não diferir? - Convém então prescrever uma função diferente a cada um, segundo sua própria natureza? - Certamente. - Como pode ser, então, que não cometeis um erro, agora, pois dizeis o contrário de vós mesmos, afirmando, por outro lado, que os homens e as mulheres devem fazer as mesmas coisas, mesmo tendo naturezas completamente distintas (separadas) $?^{8}$

Assim, a primeira onda é formulada como problema, também por um outro viés, ou seja, como uma contradição interna; não só um paradoxo relativo aos costumes, em geral, mas uma contradição na argumentação. Sócrates faz um comentário metodológico bem humorado: seja numa piscina pequena, seja no mar imenso, quem cai n'água tem que nadar; já que não vai aparecer um golfinho salvador, eles terão que buscar uma saída argumentativa (453D511). Ele admite a própria autocontradição, em três etapas. Concordaram que a naturezas diferentes cabem ocupações diferentes e que a natureza da mulher é diferente da do homem; mas ao atribuírem as mesmas ocupações a homens e mulheres, atribuem as mesmas ocupações a naturezas diferentes, o que vai contra a primeira afirmação.

O primeiro comentário é mais realista que irônico; de fato, mesmo sem querer (ákontes), eles fizeram como muitos fazem: se lançaram na antilogia, acreditando estar fazendo dialética e não erística (oíesthai ouk erízein allà dialégesthai). Ou seja, mesmo para o dialético bem intencionado, a antilogia erística é um risco permanente; a contradição não é uma escolha deliberada, é um acontecimento no processo mesmo de pensar; mas o erízein consiste em ficar preso às palavras, por oposição ao dialégesthai, que implica em examinar o que se diz e distinguir segundo as formas (kat'eíde diairoúmenoi tò legómenon episkopeîn).

7 V 452E6-453A4 - póteron dunatè phýsis he anthropine he théleia têi toû árrenos génous koinonêsai eis hápanta tà erga è oud'eis hèn è eis tà mèn hoìa te, eis dè tà ou, kaì toùto dè to peri tòn pólemon potéron estín.

8 V 453B7-C6 - éstin oûn hópọs ou pámpoly diaphérei gynè andròs tèn phýsin; - pộs d'ou diaphérei; oukoûn állo kai érgon hekatéroi prosékei prostáttein to katà tèn hautoû phýsin; - tí mén; - pộs oûn oukh hamartanete nynì kaì tanantìa hymîn autoîs légete pháskontes aû toùs ándras kaì tàs gynaîkas deìn tà autà práttein, pleiston kekhorisménen phýsin ékhontas; 
Num segundo momento, irônico agora, Sócrates diz que a antilogia é nobre (gennaía) (453E-454A). ${ }^{9}$ Por um lado, podemos entender que ele está comentando a nobreza que há em reconhecer as próprias contradições, na medida em que é ele mesmo que está lançando argumentos contrários aos seus próprios; por outro lado, há um reconhecimento da força ou do poder da argumentação por contradição, que pode impor-se mesmo contra a vontade dos próprios interlocutores. De qualquer modo, ela faz deles vítimas da contestação e prisioneiros da literalidade do que é dito, tornando-os incapazes de pensar com clareza ou com justiça; o espírito combativo (erízein), levado ao extremo, pode impedir de perceber diferenças relevantes, não levar à compreensão do problema em questão e fazer com que, em vez de desenvolverem um exame compartilhado, os interlocutores entrem em conflito uns com os outros, donde a noção de luta pela vitória na argumentação e não pelo estabelecimento da verdade. ${ }^{10}$

É preciso, então, desfazer a contradição; quando atribuíram diferentes ocupações a naturezas diferentes e as mesmas ocupações a naturezas que são as mesmas, eles não examinaram que diferença e que identidade estavam exatamente em questão: ou seja, não discutiram, nem estabeleceram o modo como se deve definir seja a espécie da natureza que (no caso) é diferente, seja a espécie da natureza que (no caso) é a mesma e a que cada uma se refere. A atribuição de ocupações foi feita a partir do estabelecimento de uma identidade suposta e de diferenças não examinadas e aceitas como verdadeiras, ou seja, de diferenças pensadas apenas no plano da dóxa:

- (a noção) que naturezas que não são as mesmas não devem ter as mesmas ocupações, nós a perseguimos com muita coragem e eristicamente, prendendo-nos às palavras, mas não examinamos de modo algum como definir a espécie da natureza (que é) diferente ou a da natureza (que é) a mesma, e a que cada uma se relaciona, no momento em que atribuímos ocupações diferentes a uma natureza diferente, e as mesmas à mesma. ${ }^{11}$

9 No Sofista, na quinta definição, o sofista é visto como praticando a antilogia e a erística (224E-226A; 231D-E); na sexta definição (231A-B) ele é alguém que pratica a purificação, através da refutação, sofísta "de linhagem nobre (génei gennaía)".

10 Sócrates faz referência aos adversários evocados em 453A-B - Queres que nós contestemos (amphisbetésomen) a nós mesmos, no lugar dos outros ...?; não é preciso que outros vos contestem (amphisbeteîn) ...

11 V 454B4-9 - to <mè̀ > tèn autèn phýsin hóti ou tôn autôn deî epitẹdeumáton tynkhánein pánu andreíos te kaì eristikôs kata tò ónoma diókomen, epeskepsámetha dè oud'hopeoûn tí eîdos tò tês hetéras te kaì tệs autês phýseos kaì pròs tí teînon horizómetha tóte, tà epitedeúmata állẹi phýsei álla, têi dè autèi tà autà apedídomen. Ana Lia Prado não aceita a correção mè em B4, e traduz: à mesma natureza não cabem as mesmas ocupações ... o que muda o viés da argumentação nesta frase, mas não seu sentido mais amplo. 
Cabe, portanto, examinar o modo como estabeleceram o que é o mesmo e o que é diferente, e o importante é perceber que há diferentes planos de diferenças, ou seja, que há diferenças diferentes. Sócrates vai mostrar que há uma natureza comum entre homens e mulheres que é anterior a certas diferenças; esta comunidade natural justifica a educação comum, assim como a atribuição das mesmas funções a ambos no governo da cidade. Ele considera que tomaram as diferenças e identidades, inicialmente, sem reconhecer quando são absolutas ou relativas, maiores ou menores, ou seja, ficando eristicamente, presos às palavras, sem examinar as diferenças entre as formas ou naturezas postas em questão através das palavras. Ele ironiza, novamente, comparando a diferença em questão com a diferença entre calvos e cabeludos, diferença risível porque não dá conta das diferenças particulares à luz da diferença em si.

... não postulamos, naquele momento, a natureza idêntica e a natureza diferente totalmente (no sentido absoluto, intensivo), mas só acompanhamos a espécie da alteridade e da semelhança relativas a essas ocupações. ${ }^{12}$

Ou seja, não perceberam a identidade ou a diferença nelas mesmas, que seria o modo correto de se proceder, mas diferenças e semelhanças menores ou parciais; a visão da forma em si ilumina os exames de casos particulares, permitindo que se percebam planos ou modalidades diferentes de diferenças; as coisas não se diferenciam sempre da mesma maneira; há que examinar cada caso; o mesmo se deve poder dizer da identidade. Há planos ou modos diferentes de semelhança ou identidade, mais ou menos parciais, mais ou menos abrangentes, e os equívocos surgem ao se tomar uma diferença parcial por outra, ou uma identidade parcial como uma identidade absoluta.

Penso que este é um dos sentidos fundamentais da ideia do bem, enquanto princípio inteligível, aplicado ao exercício cognitivo: fazer com que quem pensa saiba fazer incidir o conhecimento maior da forma (do em si) na situação particular em questão, de acordo com as exigências do problema visado; o bem é, assim, um princípio de discernimento, que permite ao indivíduo pensar e saber o que é pensável e que, assim, é o melhor; ele é o valor (cognitivo,

12 V 454C7-D1- tóte ou pántọs tèn autèn kaì tèn hetéran phýsin etithémetha, all 'ekeîno tò eidos tê̂s alloióseós te kaì homoióseos mónon ephyláttomen tò pròs autà teînon tà epitedeúmata; Ver tradução de Grube, revista por Reeve : "we did not introduce every form of difference and sameness in nature...", que compreende pántos em sentido extensivo, ou seja, da forma como classe; nesta compreensão tenta-se explicar o ridículo dizendo que a compreensão de identidade e diferença não eram abrangentes o suficiente; não se considerou todos os casos possíveis, apenas alguns; uma leitura de inspiração claramente empirista ou quantitativa. Plato. Complete works (ed. Cooper), 1997. 
discriminador) maior que permite a inteligibilidade e o exame dos seres e dos valores em questão, caso a caso. ${ }^{13}$

Sócrates compara, em seguida, outra diferença com a diferença em questão, para mostrar como são diferenças diferentes. O exemplo parece banal, mas evidencia os sentidos diferentes nos quais se usa o termo «natureza»e ilustra o «parecer diferir». Compara um médico a outro médico, dizendo que ambos têm a mesma natureza; e compara um médico e um carpinteiro, dizendo que têm naturezas diferentes. Os dois médicos têm a mesma natureza com relação às ocupações (um caso de homoíosis); mas um médico e um carpinteiro têm naturezas diferentes, também com relação às ocupações (um caso de allóiosis); trata-se de uma determinação ulterior da natureza humana, especificada no que concerne às ocupações, mas que não deve ser confundida com as semelhanças ou diferenças, em outros planos, ou relativas a aspectos diferentes das mesmas naturezas.

Portanto, disse eu, com relação ao gênero dos homens e ao das mulheres, se ele (um deles) parece diferir em relação a (o exercício de) tal técnica ou tal ocupação, diremos que efetivamente se deve atribuir esta ocupação a um ou ao outro. Mas se só parece diferir neste único ponto, a saber, que o gênero feminino procria e que o masculino gera, diremos que não foi de modo algum demonstrado, por isso, que a mulher difere do homem, quanto ao que dissemos, e continuaremos a acreditar que nossos guardiões e suas mulheres devem se ocupar das mesmas coisas. ${ }^{14}$

Diferenças em um plano, ou segundo um aspecto, podem levar a se supor que haja diferenças em outros planos ou segundo outros aspectos; para se estabelecer qualquer plano de semelhança ou identidade, é inevitável que se atravesse os múltiplos planos de alteridade; a identidade dialética só se constitui nessa rede de diferenças construídas dialogicamente. ${ }^{15}$

13 A meu ver, este é um sentido importante de VI 508D-E. A alma, quando ela se fixa naquilo que a verdade e o ser iluminam, ela o concebe, o reconhece (e parece que ela possui inteligência); mas quando ela se fixa naquilo que é misturado com a obscuridade, o que vem a ser e se desfaz, ela só tem opinião e se torna obscura também, suas opiniões variam para um lado e para outro (e ela parece com um ser que não tem inteligência). O papel do bem é permitir que a alma exerça sua inteligência, marcando os seres com inteligibilidade, conferindo verdade aos objetos conhecidos, ou seja, proporcionando a possibilidade de se discernir os objetos que podem ser efetivamente conhecidos; sua ação é tornar possível a diferença que o objeto inteligível significa; o inteligível e também seu conhecimento, discernindo inteligíveis e visíveis em meio à multiplicidade de seres (atos, eventos e processos) mais ou menos semelhantes, mais ou menos distintos.

14 V 454D7-E4 - oukoûn, ện d'egó kaì tò tôn andrôn kaì tò tôn gynaikôn génos, eàn mèn pròs tékhnen tina è állo epitédeuma diaphéron phaínetai, toû dè phésomen hekatéroi deîn apodidónai, eàn d'autoi toútoi phaínetai diaphérein, toi tò mèn thêly tíktein, tò dè árren okheúein, oudén ti pó phésomen mâllon apodedeikhthai hós pròs hò hemeîs légomen diaphérei gynè andrós, all 'éti oiesómetha deîn tà autà epitédeúein toús te phýlakas hemîn kaì tàs gynaîkas autôn.

15 Como mostra de modo cabal e complementar à República, em diversos momentos, o Sofista. 
Interessa-me particularmente o «parece diferir» (diaphéron phaínetai; phaínetai diaphérein); a oposição decisiva na passagem não é simplesmente entre parecer e ser, mas entre parecer diferir e diferir mesmo; a elaboração dialética do que é inteligível (em relação ao ser humano, no caso) desenvolve-se no campo tridimensional do ser, do mesmo e do outro; o (a)parecer faz parte de três oposições e se insere numa trama que reúne 'parecer ser', 'parecer ser o mesmo' e 'parecer diferir', de modo complementar.

Sócrates propõe um desafio ao suposto contraditor: ele deve dizer em relação a que ocupação (prós ti), na organização da cidade, a natureza da mulher e do homem não são as mesmas, mas diferentes. Este personagem que "diz o contrário" (tà enantía légonta), antes indicado como residindo dentro do próprio Sócrates, agora aparece como alguém separado, um outro qualquer. O desafio é que o suposto contraditor siga a discussão para ver se (os interlocutores) são capazes de demonstrar que nenhuma ocupação é própria da mulher, no sentido de ser exclusiva da mulher, por causa de sua natureza, na administração da cidade. São apresentados três critérios para se estabelecer o que é um bom natural: aprender facilmente, descobrir muito no assunto que se aprende e fazer de modo com que as funções do corpo se ponham a serviço do pensamento de modo satisfatório. ${ }^{16}$

Opondo dois tipos, ele diz:

num, as coisas relativas ao corpo se poriam a serviço do pensamento de modo satisfatório, sendo que no outro elas se oporiam (ao pensamento)? ${ }^{17}$

\section{Finalmente:}

Não há, meu amigo, nenhuma ocupação daqueles que administram uma cidade que seja própria de uma mulher, porque ela é mulher, nem de um homem porque ele é um homem; mas as naturezas são igualmente distribuídas entre as duas ordens de seres vivos; a mulher participa de todas as ocupações, e isto conforme a natureza, e

16 Adam adota a posição segundo a qual é Platão quem, de diversas maneiras, retoma os temas dos livros I-IV, já tendo conhecimento da comédia Assembléia de mulheres, de Aristófanes. Ele considera que Assembléia de mulheres é uma crítica tanto à democracia ateniense quanto às teorias socialistas da época e que Platão retoma, seriamente, quase todas as propostas feitas, comicamente, pelo personagem principal de Aristófanes. O comentador faz aproximações temáticas e linguísticas entre os dois textos; considera que Platão certamente tinha em mente o texto cômico quando escreveu sobre mulheres e crianças; acredita, contra Aristóteles, que os temas da comunidade de mulheres e crianças, assim como de propriedades, não são originais de Platão. Adam, 1902, Apêndice I ao livro V, p.345-355. Ele ainda sugere que a referência a uma base natural para a reorganização da sociedade era um motivo comum à época de Platão, mas não parece distinguir o sentido específico que Platão confere à noção de "natureza", enquanto relativo à "natureza inteligível" dos seres. Para um estudo mais amplo sobre a transformação que o sentido de natureza sofre em Platão, ver Dixsaut, 1994.

17 V 455B9-C1 - kaì tôi mèn tà toû sómatos hikanôs hyperetoî têi dianoíai, tôi dè enantioîto. 
o homem também de todas, mesmo que, em todas, a mulher seja mais fraca que o homem. ${ }^{18}$

Diversas ocupações e aspectos são mencionados e analisados, mostrando, entre outras coisas, que, em tudo, um dos sexos é melhor do que o outro (polý krateîtai en hápasin tò génos tô̂ génos), embora muitas mulheres, em muitas áreas, sejam melhores que muitos homens (gynaîkes méntoi pollaì pollôn andrôn beltious eis pollá). Considera-se a medicina, a música, a ginástica e a guerra, a filosofia (uma mulher ama o saber e outra o odeia - philósophós te kaì misósophos), a relação com os afetos, a proteção da cidade.

Sócrates fala de natureza em pelo menos dois planos diferentes. As naturezas (hai phýseis), múltiplas, são igualmente distribuídas, ou seja, pensa-se a natureza em relação a dimensões particulares (ou mais ou menos particularizantes); uma ocupação, como, por exemplo, a proteção da cidade (eis phylakèn póleos) (o tradutor francês Pachet fala de um natural "adaptado" à guarda da cidade). Já a natureza pensada como uma (única) sustenta a distribuição igual de homens e mulheres, em todas as ocupações; o singular sugere um outro plano, segundo o qual (katà phýsin), quaisquer dimensões particularizantes estariam justificadas e, de algum modo, superadas (ou ultrapassadas). Me parece claro que o argumento aponta para uma natureza humana inteligível, segundo a qual as diferenças entre homens e mulheres não são tais que impeçam que eles exerçam funções iguais na condução da cidade.

Sócrates chega mesmo a inverter as avaliações, considerando a situação de fato da cidade como algo contra a natureza (parà phýsin - 456C1-2). A conclusão a que chegam en tois lógois é, portanto, que o mesmo treinamento será apropriado para homens e mulheres; se suas capacidades naturais são as mesmas, nossos guardiões, pela educação que recebem, são os melhores; as mulheres, se receberem a mesma educação, serão as melhores mulheres. ${ }^{19}$

Ora, para que uma mulher se torne guardiã, não haverá entre nós uma educação para fabricar homens (com suas ocupações) e outra mulheres, principalmente se ela cuidar da mesma natureza (humana)? ${ }^{20}$

18 V 455D6-E2 - oudèn ára estín, ô phíle, epitédeuma tôn pólin dioikoúnton gynaikòs dióti gyné, oud'andròs dióti anér, all'homoíos diesparménai hai phýseis en amphoîn toîn zôiioin, kaì pánton mèn metékhei gynè epitedeumáton katà phýsin, pánton de anér, epì pâsi dè asthenésteron gynè andrós.

19 Proclo, em seu Comentário à República, fala de unidade e identidade de espécie, de virtude e de educação; educação essa que é possível e vantajosa. VIIla. Dissertação, 236-257.

20 V 456C11-D1 - oukoûn prós ge tò phylakikèn gynaîka genésthai, ouk álle mèn hemîn ándras poései paideía, álle dè gynaîkas, állos te kai tèn autèn phýsin paralaboûsa; 
Não há nada melhor para uma cidade do que ser habitada pelos melhores homens e mulheres e este fim será alcançado pelo mesmo sistema de educação, mas que leve em conta as diferenças relativas (457A6-7). É então preciso que as mulheres dos guardiões se desnudem, "pois se vestirão com excelência, em vez de roupas". ${ }^{21}$

A primeira onda termina sutilmente, com Sócrates parafraseando Píndaro e devolvendo a crítica à comédia, pois o homem que ri ao ver mulheres se exercitando nuas "colhe um fruto do ridículo que não está ainda maduro»; aparentemente ele não sabe do que ri, nem o que está fazendo. ${ }^{22} \mathrm{O}$ humor da comédia provoca um riso fácil e rápido demais, é mal acabado. O que é verdadeiramente ridículo é não determinar o que é bom para a cidade através do exame inteligível, acessível através do pensar e da reflexão e que só aparece en tois lógois.

Sócrates acredita ter evitado ser submerso pela primeira onda.

Em síntese, podemos dizer que há pelo menos dois planos fundamentais nos quais podemos pensar o conceito de natureza (phýsis), no livro V, distinção que é retomada e reforçada pelo final do livro, quando são estabelecidas as diferenças entre os objetos da opinião e da ciência. Por um lado, a natureza pensada como essência, que unifica o gênero humano (452E6-453A4) e que efetivamente justifica a formação comum a homens e mulheres; natureza constitutiva e unificante, que reaparece na natureza do belo em si e que se opõe à multiplicidade de coisas belas (V 476B4-8). Por outro lado, as naturezas particularizantes e distintas do homem e da mulher, que justificam suas funções reconhecidamente diferentes na cidade hoje (V 453B7-C6). Nessa segunda dimensão, podemos ainda incluir, por exemplo, a natureza da prática (das coisas) que aproxima-se menos da verdade que (sua) descrição (473A1).

Portanto, efetivamente, parece que a configuração inicial do livro V pensada como paradoxal prepara ou constrói o ambiente argumentativo necessário para a posição da diferença decisiva entre dóxa e epistéme, ao final. $\mathrm{O}$ enfrentamento da primeira onda já prepara a proposta política de que o filósofo deve governar a cidade, por possuir um conhecimento que é diferente dos julgamentos aceitos sem reflexão ou discernimento pelos cidadãos. Contrapor e questionar o que é visto "nos olhos" com o que é pensado "nos argumentos" é um modo de opor-se à dóxa e desenvolver a epistéme, sem que isso signifi-

21 V 457A6-7 - epeíper aretèn anti 'himation amphiésontai.

22 V 457B2-4 - atelệ toû geloíou drépon karpón. Píndaro, fr.209, critica os fisiólogos que colhem o fruto prematuro da sabedoria - atelê sophías drépon karpón, ou seja, cujo saber não é um saber de verdade. Ver Adam, 1963, p.291. 
que a redução da opinião ao seu aspecto fenomênico (ou empírico) ou tomar a concepção da ciência de modo dogmático (absoluto) ou determinado por uma identidade unívoca (o ser sendo confundido com "ser o mesmo que"). Pensar através de paradigmas exige o exame crítico dos juízos aceitos como bons e verdadeiros, inclusive aqueles que estruturam a cidade no que ela tem de mais fundamental (sua proteção guerreira). Com relação às suas naturezas, há diferenças entre homens e mulheres, mas há também semelhanças; há diferenças diferentes e semelhanças diferentes; ser capaz de discriminar essas diferenças é decisivo para se compreender melhor as naturezas (de cada um) e a natureza que lhes é comum, sua identidade inteligível.

\section{Referências}

Platonis Opera. Burnet, I-V. Oxford: Clarendon Press, 1900-1907. PLATÃO. A República. Trad. Ana L. Prado. São Paulo: Martins Fontes, 2006.

PLATO. Complete works. Ed. J. M. Cooper. Indianapolis / Cambridge: Hackett, 1997.

PLATO. The Republic of Plato. Transl. J. Adam. Cambridge: C.U.P., (1902) 1963. PLATON. La République. Trad. P. Pachet. Paris: Gallimard, 1993.

ARISTOPHANES. Ecclesiazusae. Ed. Transl. A. H. Sommerstein. Warminster: Aris \& Phillips Ltd., 1998.

PINDAR. Olympiques. Pythiques. Nemeennes. Isthmiques et fragments. Trad. A. Puech. Paris: Les Belles Lettres, 1949-1992.

PROCLUS. Commentaire sur la République. Trad. A. J. Festugière. Paris: Vrin / CNRS, 1970.

DIXSAUT, Monique. Le naturel philosophe. Paris: Les Belles, (1985) 1994.

DIXSAUT, M. Qu'appele-t-on penser? Cahiers Philosophiques de Strasbourg 3 (1995) p.214-215.

MARQUES, Marcelo P. La phantasia chez Platon. In: VEGLERIS, Eugénie. (Ed.) Cosmos et psychè. Mélanges offerts à Jean Frère. Hildesheim: Georg Olms Verlag, 2005, p.123-141.

MARQUES, M. P. Platão, pensador da diferença. Belo Horizonte: Ed. UFMG, 2006.

MARQUES, M. P. Entre ser e aparecer: sobre República V. In: SANTOS, Marcos M. (Org.) I Simpósio de Estudos Clássicos da USP. São Paulo: Associação Editorial Humanitas / Fapesp, 2006b, p.247-270.

MCINTYRE, Alasdair. Justiça de quem? Qual racionalidade? Trad. Marcelo P. Marques. São Paulo: Ed. Loyola, 1991.

WHITE, Nicholas, C. Plato's metaphysical epistemology. In: R. Kraut (ed.). The Cambridge Companion do Plato. Cambridge: CUP, 1992, p.277-310. 